\title{
A XXVII Semana do Meio Ambiente da PUC-Rio sob o olhar dos alunos: o trabalho da Universidade frente à pandemia da COVID-19
}

Eva Aparecida Rezende de Moraes ${ }^{1}$

A pandemia em nosso país, que se iniciou em março de 2020, já dura mais de um ano - e, ao que parece, devido à lentidão da aplicação da vacina, vai durar um tempo ainda (em 23 de junho de 2021, o Brasil ocupava o 68이 lugar no ranking mundial) (CNN, 2021). Praticamente todas as instituições em nosso país foram afetadas - principalmente as de ensino. Diante deste enorme desafio, a Reitoria da PUC-Rio e o NIMA (Núcleo Interdisciplinar de Meio Ambiente) escolheram o tema da XXVII Semana do Meio Ambiente: Ética socioambiental nas universidades em tempos de pandemia. O propósito foi apresentar as ações dos quatro Decanatos da Universidade e de três redes católicas frente a mesma: o SACRU (Strategic Alliance of Catholic Research Universities), AUSJAL (Asociación de Universidades Confiadas a la a Compañía de Jesús en América Latina) e OLMA (Observatório Nacional de Justiça Socioambiental Luciano Mendes de Almeida). Este simples artigo é para partilhar as impressões que alguns alunos tiveram dos webinares (serão citadas apenas as abreviaturas dos nomes e sobrenomes dos alunos): uma das atividades da avaliação do período com meus alunos das turmas de CRE1141 (Ética Cristã) e CRE1175 (Ética Socioambiental e Direitos Humanos) da Cultura Religiosa (CRE) foi o relatório de um webinar desse evento. Aliás, peço desculpas por usar o pronome na primeira pessoa.

\section{A partilha dos alunos referente ao $1^{\circ}$ dia $-01 / 06 / 2021$}

A XXVII Semana do Meio Ambiente da PUC-Rio foi aberta oficialmente pelo Grão-Chanceler Cardeal Dom Orani Tempesta, seguido do Reitor da PUC-Rio Padre Josafá Carlos de Siqueira e pelo Diretor do NIMA Professor Felipe Guanaes. O aluno O.L.M.S. destacou, na abertura feita por Dom Orani Tempesta: a importância da realização da Semana do Meio Ambiente e da ética socioambiental desenvolvida na PUC-Rio, e a dificuldade no enfrentamento da pandemia na cidade do Rio de Janeiro, devido às diferentes realidades existentes. D. Orani também apresentou a origem e a importância da Encíclica Laudato sí do Papa Francisco (publicada em 2015), que tem como uma das suas principais mensagens: "não deixar que o jardim de Deus se torne um deserto", defendendo o cuidado com o mundo em que vivemos. Chamou a atenção do aluno acima referido o relato do Cardeal sobre as diferentes atividades ambientais realizadas pela Arquidiocese - como o plantio de árvores em diferentes áreas da cidade e a triagem do lixo coletado. Em seguida, tivemos as colocações do professor Felipe Guanaes, que explicou como

\footnotetext{
${ }^{1}$ Doutora em Teologia pela PUC-Rio e professora do Departamento de Teologia da PUC-Rio (Setor de Cultura Religiosa).
} 
a XXVII Semana do Meio Ambiente foi estruturada: a primeira parte foi composta por palestras (para estimular e sensibilizar o público para mudanças de hábito em prol de um desenvolvimento sustentável) e, a segunda, mostrou ações pontuais dos quatro Decanatos da PUC-Rio frente à pandemia. Logo após, tivemos a abertura feita pelo Reitor pe. Josafá Siqueira, que agradeceu ao NIMA e aos expectadores, e defendeu três razões para a realização da XXVII Semana: celebrar (mesmo em clima de perplexidade diante da pandemia, principalmente quanto ao número de mortos), como sinal de alerta (para mudarmos nossos maus hábitos) e com esperança (para não retrocedermos na questão do meio ambiente frente aos negacionismos).

O Reitor Padre Josafá Siqueira, além de participar da Abertura oficial, proferiu a primeira Palestra da XXVII Semana: Os desafios para a universidade pós pandemia. A aluna V.F.C.B.R. partilhou destaques da palestra: o Reitor destacou que, desde a I Semana do Meio Ambiente, havia o objetivo de construir uma Universidade antenada e articulada com os grandes problemas socioambientais, e chamou a atenção a marca da esperança nas palavras do Reitor: há muitas possibilidades de mudanças diante dos avanços da tecnologia e da crescente consciência ambiental. A aluna deu ênfase à opinião do Reitor: a de que este vírus tem humilhado o ser humano, mostrando a nossa incapacidade; mas também há esperança: não há como retroceder em todo o avanço que a sociedade mundial desenvolveu em termos de meio ambiente - apesar do perigo de retrocesso em nosso país. A universidade é o "local do saber" e temos que repensar os poderes educativos, preservando os Direitos Humanos e a Justiça com a Criação de Deus. Reitor sabe que a nossa Universidade enfrentará desafios socioambientais depois da pandemia, visto que ela mexeu muito com a dinâmica da Comunidade acadêmica e apresentou os principais desafios futuros: "Intensificar um maior diálogo entre os diferentes campos científicos, com uma preocupação maior pela interdisciplinaridade no ensino e na pesquisa; construir um novo humanismo, dentro de uma visão sistêmica; e saber planejar com horizonte de futuro". A aluna destacou algumas atitudes sugeridas pelo Reitor: ênfase maior nos debates e práticas interdepartamentais sobre mudanças climáticas e os impactos socioambientais e valorizar mais o potencial do campus para ampliar e amadurecer os estudos e pesquisas integradas nas áreas humanas, sociais, tecnológicas, biológicas e da saúde. Segundo, ainda, o Reitor, a PUC-Rio foi a primeira Universidade do país a criar uma Agenda Ambiental e, após a pandemia, deverá ser feita uma revisão da mesma: dar maior visibilidade nacional e internacional aos projetos socioambientais da PUC-Rio e apoiar mais as novas tecnologias sustentáveis em energia e biodiversidade (materiais inteligentes, biotecnologia, inteligência artificial, design sustentável, economia sustentável, incubadoras virtuais, aplicativos inteligentes, entre outros).

Após a Abertura oficial, aconteceu outra palestra: Princípios socioambientais na SACRU no contexto da pandemia, com Pier Sandro Cocconcelli; ele discursou em italiano e alguns alunos disseram ter tido dificuldade para compreender e acompanhar. Segundo a aluna A.S., o Professor Cocconcelli apresentou detalhes importantes sobre os princípios socioambientais da SACRU no contexto de pandemia e, por isto, ela conseguiu ter uma noção mais ampla de como 
as ações promovidas causam impactos positivos para o mundo: o SACRU é uma grande estrutura, com diversos setores - como agricultura, clima e qualidade de vida. Outra colaboração sobre o pesquisador de microbiologia Professor Cocconcelli, trago da aluna V.F.C.B., que destacou a ênfase dada pelo Professor a um novo paradigma da ciência: mais aberta e transparente, responsável e inovadora, tendo o "network" e o internacionalismo como essenciais. O Professor realçou um dos papéis principais do SACRU atualmente: planejar as atividades das Universidades Católicas em prol de um desenvolvimento sustentável no contexto da pós pandemia (esta foi, inclusive de um estudo do SACRU); outra missão é promover a cooperação global entre os parceiros, para impulsionar o conhecimento e a educação superior a nível global para o bem comum. Finalizando, foi apresentada pelo Professor Cocconcelli uma abordagem tripartida sobre desenvolvimento sustentável: conhecimento - cultura - ética.

Após as palestras do convidado, tivemos a apresentação das ações de dois Decanatos da PUC-Rio frente à pandemia da COVID-19. O Centro Técnico Científico (CTC) ficou a cargo do Decano Sidnei Paciornik e chamou a atenção do aluno Y.R. - como a colocação inicial de que "a crise ambiental tem um impacto muito maior do que a própria crise global do Corona Vírus, e poucas pessoas estão tendo ciência disso". O Professor destacou a Campanha de Inclusão Digital, que tem sido muito importante no apoio aos alunos que necessitam de computadores e planos de internet ao longo da pandemia - um desafio abraçado pela Universidade. Em seguida, apresentou as técnicas científicas usadas por seus Departamentos: o de Engenharia Química e de Materiais está pesquisando novos métodos de redução da poluição, usando catalisadores, geração limpa de hidrogênio e processos de simulação de produção de biogás; vários projetos foram destacados: Cinética das reações de passivação de escórias de aciarias LD (para preservar a saúde dos trabalhadores da construção civil), Reciclagem dos efluentes de drenagem das operações de passivação das escórias de aciaria LD (para reutilização das águas nas indústrias), Tratamento a quente de escórias de aciaria LD, Desenvolvimento de Aglomerados autorredutores, Processos efetivos de degradação de biomassa e materiais eletrônicos (um dos passivos ambientais mais importantes que existem hoje em dia), Uso de peróxido de hidrogênio, Uso de Biosulfactantes no tratamento mineral (que permite a recuperação de áreas afetadas pela mineração) e Uso de redes neurais artificiais para a detecção e diagnóstico de falhas de eletrocoagulação. O Departamento de Engenharia Elétrica tem utilizado inteligência artificial para a detecção de desmatamento de florestas e vazamentos de óleo e tem trabalhado com modelagem para o uso de energias limpas. No Departamento de Engenharia Industrial, foram destacados os trabalhos de Otimização de recursos energéticos, Reciclagem doméstica e Cadeias de suprimentos, e o de Química tem desenvolvido Métodos analíticos para contaminantes orgânicos persistentes em amostras ambientais (muito elogiado pelo aluno acima citado, porque monitora áreas afetadas por desastres ambientais marinhos). $\mathrm{A}$ aluna V.C.C.S partilhou a apresentação do Professor Hilton Koch - Decano do Centro de Ciências Biológicas e da Saúde. O Professor destacou que os profissionais de medicina da 
PUC-Rio, logo no início da pandemia, participaram de lives abordando a situação dos profissionais na linha de frente, a saúde mental em período de isolamento e outros temas; além disto, foi criada uma página com conteúdo específico sobre COVID no site da MEDPUC. A Medicina da PUC também realizou diversos webinars com professores e especialistas convidados e criou uma série de vídeos no YouTube, chamados "Conversando sobre coronavírus", com especialistas brasileiros que estão trabalhando em diferentes países.

Encerrando o primeiro dia, tivemos a premiação do IV Concurso de Projeto Socioambiental no campus da PUC-Rio 2021 - uma parceria entre a disciplina CRE1175 e o NIMA. Esta premiação foi conduzida pelo Professor Pe. Abimar Oliveira de Moraes, Coordenador da CRE. A aluna A.C.C.B. partilhou suas impressões desta premiação. Pe. Abimar contextualizou como o Departamento de Teologia interage com a Semana do Meio Ambiente através de uma união entre fé, ética e sociedade - principalmente na atualidade, quando a crise socioambiental é de suma importância. Em seguida, a Professora Mônica Campos explicou que a ideia de um Concurso de Ideais Socioambientais para o Campus da PUC-Rio nasceu junto com a disciplina CRE1175, com o objetivo de pensar novas ideias para a Comunidade acadêmica se tornar cada vez mais sustentável. O Edital e a Inscrição ocorrem após o período da G2; a equipe do NIMA analisa os Projetos inscritos e os classifica em 1ำ $2^{\circ}$ e $3^{\circ}$ lugares. Em seguida, a Professora Mônica mostrou os Projetos vencedores nas três edições anteriores do Concurso e seus benefícios para a Universidade. Por fim, a Professora Melissa Casacchi, assessora técnica do NIMA, relatou como foi o Concurso ano passado e este ano (mesmo com pandemia, não deixou de ser realizado); apresentou o Edital, avaliou a originalidade e o impacto das Ideias Socioambientais dos vencedores e apresentou os alunos premiados deste IV Concurso: primeiro lugar - "Núcleo de Voluntariado Ambiental e Social (NuVAS)", dos autores: Ana Leticia Wanderley; Ana Luiza Fernandes; Cléo Berni; Luiz Augusto; Luíza Macedo; Pedro Rocha; Rodrigo Barbosa; segundo lugar - "O Passaporte do Bosque: (Re)conhecendo o espaço do campus universitário como turista", de Thayna da Costa e Silva; terceiro lugar - "Conjunto tartaruga", dos autores: Gabriel Brandão da Silva e Helena de Lima Montero Rodriguez.

O aluno R.T.S., ao assistir a este primeiro dia, partilhou sua satisfação em ter acesso a informações que Ihe eram desconhecidas: ele está há quatro anos na Universidade e somente agora teve conhecimento de tantos projetos socioambientais! Por fim, ressaltou a importância de os alunos criarem soluções inovadoras e sustentáveis - como o Água Camelo, projeto dos alunos do Design e que já ajuda famílias em várias partes de nosso país (aguacamelo.com.br).

\section{A partilha dos alunos referente ao $2^{\circ}$ dia $-02 / 06 / 2021$}

A abertura do segundo dia foi a apresentação do Coral Alegria, com crianças da Rocinha, organizada pelo Assessor de Direção do NIMA Fernando Coutinho, e que impactou positivamente o aluno V.L.P.S. Este Coral foi formado em 2003, através do engajamento de 
jovens e crianças da Rocinha e do Parque da Cidade - Comunidades adjacentes à nossa Universidade; este Coral tem convênio com a PUC-Rio, por meio do NIMA e do NEAM (Núcleo de Estudo e Ação sobre o Menor) - o que tem proporcionado aos adolescentes e jovens dessas localidades acesso à nossa Universidade. Para o aluno acima referido, é uma forma muito boa de crescimento para essas crianças e esses jovens, uma possibilidade de ter acesso à faculdade e à cultura e transformar suas vidas. O Coral Alegria cantou três músicas: Trevo (de Ana Vitória), Vilarejo (de Marisa Monte) e Cores da Manhã (de Tibor Fittel); por conta das restrições da pandemia, somente 13 meninas e um menino se apresentaram, e todos usavam máscaras.

Em seguida a esta belíssima apresentação, tivemos a Conferência do Professor Padre Luiz Arriaga, presidente da AUSJAL e Reitor do ITESO (Universidad Jesuita de Guadalajara, no México), com o título: A pandemia e as universidades da AUSJAL. Além de comentar as atividades realizadas pela AUSJAL, o Professor Arriaga afirmou que a desigualdade social na América Latina tem relação com as injustiças ambientais. Apresento aqui as impressões da aluna C.G.G., relatadas em seu relatório; segundo ela, o Professor partilhou que o contexto de desigualdade na América Latina se agravou durante a pandemia, levando mais pessoas à situação de pobreza e ao abandono das escolas por não terem acesso à sala de aula online. Ele destacou algumas advertências ambientais que a Ciência tem apresentado: se as práticas ambientais não melhorarem, o número de mortes prematuras aumentará muito; podemos estar chegando ao ponto de não haver mais retorno na questão da destruição do meio ambiente. Algumas causas de nossa situação atual foram apontadas na palestra pelo Professor: a separação antropocêntrica entre meio ambiente e seres humanos (a destruição ambiental é uma consequência da ganância humana) e a crise da civilização (migração forçada de pessoas de suas comunidades). Os problemas sociais e ambientais então absolutamente entrelaçados: a crise ambiental implica também em uma questão política e de Direitos Humanos e as soluções devem passar por uma reflexão sobre as formas de produção injustas na sociedade; esta crise pode ser revertida se a humanidade tomar as atitudes necessárias - um dever de todos e, especialmente das Universidades, por serem campos especiais para se pensar e construir alternativas para uma sociedade mais sustentável. Para criar uma cultura mundial digna, devemos: transformar a maneira que entendemos a dimensão socioambiental, articular as disciplinas para transformar radicalmente as formas de produção e de consumo, criar standards internacionais para a defesa dos "eco direitos", promover reflexão rigorosa e ativa e o diálogo entre a fé e a ciência. E, quanto aos desafios da América Latina frente ao COVID, o Professor Arriaga propõe as seguintes alternativas: efetivar políticas públicas, desenvolver a colaboração científica e tecnológica, assegurar os Direitos Humanos e denunciar ações e posturas inadequadas dos governos e grupos poderosos. A aluna encerra seu relatório com a mensagem final deixada pelo Professor Arriaga: "Nós somos a terra, nosso corpo é constituído pelos elementos da terra! Devemos ter humildade e nos considerar iguais aos outros seres". 
Em seguida, aconteceu a palestra Desafios socioambientais e a pandemia - a atuação da rede de Justiça Socioambiental da Província dos Jesuítas do Brasil, com Felipe Lacerda, representante do OLMA, da Cátedra Laudato Si da UNICAP (Universidade Católica de Pernambuco). Escolhi o relatório da aluna A.C. sobre esta palestra; ela destacou que, para Felipe Lacerda, "o Observatório é um núcleo articulador de instituições e iniciativas em rede focadas em temáticas comuns ligadas à promoção da justiça socioambiental da Rede de Promoção da Justiça Socioambiental da Província dos Jesuítas do Brasil". A Secretaria Global possui vários estudos das ações dos jesuítas no mundo inteiro e produziu atividades durante o período de pandemia do COVID-19. Felipe Lacerda apontou algumas ações concretas da Rede na pandemia: Projeto OCA (Oficinas Culturais Anchieta), SARES (Serviço Amazônico de Ação, Reflexão e Educação Socioambiental), Centro Jesuíta De Cidadania e Assistência Social, Centro de Promoção de Agentes de Transformação, Projeto Social Centro Santa Fé, Centro de Estudos e Ação Social, Centro Alternativo de Cultura. O Projeto que mais chamou a atenção dessa aluna foi o "Centro de Estudos e Ação Social", que atuou na prevenção do COVID-19 e segurança alimentar, com uma proposta de aliança dos povos do campo e da cidade no Estado da Bahia: articulando com movimentos sociais, arrecadaram 6,4 toneladas de alimentos agroecológicos e doadas ao Sul da Bahia e 3 toneladas de alimentos agroecológicos para 325 famílias em situação de insegurança alimentar residentes em áreas de conflito fundiário na capital baiana; também houve a produção de 1500 litros de álcool $70^{\circ}$ que beneficiaram 3 mil famílias e a produção de 600 máscaras reutilizáveis de tecido feitas pelas trabalhadoras rurais e costureiras das comunidades. Felipe Lacerda deixou sua mensagem final: "Em que posso servir?" - frase importante, em um país marcado pelas desigualdades socioambientais.

Após a palestra deste convidado, dois Decanatos da PUC-Rio apresentaram suas ações diante da pandemia da COVID-19. A apresentação do Centro de Ciências Sociais (CCS) foi feita pelo Decano Luiz Roberto Cunha. O Professor começou apresentando, através de um vídeo, as atividades socioambientais e de acompanhamento da COVID desenvolvidas pelo CCS; a aluna R.O. destacou: o Departamento de Comunicação - que faz trabalhos em sala de aula sobre os impactos ambientais do lixo doméstico e oferece a disciplina "Comunicação e Meio Ambiente", ministrada pelo professor e jornalista André Trigueiro; o do Direito - que tem pesquisado argumentos válidos para a inserção da variável climática no licenciamento ambiental; o de Economia - que tem o NAPC (Núcleo de Avaliação de Políticas Climáticas), o de Geografia e Meio Ambiente - que trabalha em pesquisa sobre o legado histórico na paisagem da Mata Atlântica; o de História - que promoveu a aula inaugural de 2020.2 sobre a Covid-19; e o de Relações Internacionais - que tem o programa de debates sobre mudanças climáticas. Dentre os projetos apresentados no vídeo, o aluno P.H.T. destacou o "ELO Rocinha" (que arrecada comida para necessitados) e os do Departamento de Economia - aliás, o aluno se surpreendeu, porque não conhecia o "lado socioambiental" deste Departamento, sendo o NAPC o que mais chamou sua atenção, por acompanhar há dez anos a eficácia de políticas públicas. Para 
complementar a apresentação, o Decano passou a palavra ao professor do Departamento de Economia Juliano Assunção, que coordena o NAPC e a CPI (Climate Policy Iniciative). Segundo o Professor Juliano, o tema do meio ambiente foi adotado por diversas linhas acadêmicas, como a Administração (que criou o conceito ESG: Environmental, Social and Governance), as Ciências Objetivas (que pesquisam como diminuir o impacto humano) e a Economia (que tem investido tempo e expertise na questão ambiental). O Professor administra o "Amazonia 2030", que elabora planos de preservação da Amazônia que são entregues à Presidência da República e aos Governadores dos Estados que abrigam a Amazônia; o NAPC está expandido o trabalho para áreas de Dinâmica Agrícola e Ocupação do Solo. Por fim, o Professor citou um projeto em parceria com o Banco Central de alocação do crédito rural em interação com a preservação do meio ambiente. O aluno F.P., por sua vez, teve sua atenção voltada para o geógrafo Alexandro Solórzano, que apresentou diversos grupos de pesquisa socioambiental da PUC-Rio em comunidades vulneráveis no Rio de Janeiro (como os Caiçaras, em Paraty): um total de dezoito ações, sendo cinco referentes à temática da pandemia.

A apresentação do Centro de Teologia e Ciências Humanas (CTCH) foi feita pelo Decano Júlio Diniz. Ainda seguindo a partilha do aluno F.P., o Professor Júlio nos apresentou os diversos projetos desse Decanato - como as iniciativas de inclusão social, no âmbito das Ciências Humanas e Sociais. Em seguida, nosso Decano apresentou o Instituto de Estudos Avançados em Humanidades e seus diversos projetos sociais, baseados na interdisciplinaridade e nas humanidades - como o inserido no Complexo do Alemão, onde mapearam as mulheres empreendedoras para auxiliá-las nos aspectos financeiros. O referido aluno disse que foi muito bom ter a participação de pessoas qualificadas e que atuam de forma direta na melhoria das práticas socioambientais e que é muito gratificante fazer parte de uma faculdade que age de diversas formas para um mundo melhor. A aluna A.B.C. também realçou a apresentação do $\mathrm{CTCH}$, achou interessantes a pluralidade e a diversidade de ações; um Departamento que chamou sua atenção foi o de Artes e Design, que promoveu ações em conjunto com outros Departamentos e Órgãos da cidade do Rio de Janeiro - como, por exemplo, a Clínica da Rocinha; o de Filosofia e outros Departamentos estão elaborando projetos visando o póspandemia. Segundo o Decano, as áreas de licenciaturas e os estágios sofreram bastante na pandemia e os Departamentos de Psicologia e de Teologia foram muito presentes, principalmente na área do prosseguimento do trabalho de ensino e pesquisa.

Como encerramento, tivemos o Momento de Oração Partilhado, coordenado pelo $\mathrm{Pe}$, Abimar de Oliveira Moraes e apresentado por mim, com testemunhos de alunos e professores sobre a experiência da pandemia da COVID-19. O aluno A.F.M. gostou deste momento; destacou que eu chamei a atenção para o fato de termos construído pontes diante da situação pandêmica;

\footnotetext{
2 "Amazônia 2030 é uma iniciativa conjunta do Instituto do Homem e do Meio Ambiente da Amazônia (Imazon) e do Centro de Empreendedorismo da Amazônia, com a Climate Policy Iniciative (CPI) e o Departamento de Economia da PUC-Rio, buscando elaborar um plano de desenvolvimento sustentável para a Amazônia brasileira e atingir o uso sustentável dos recursos naturais em 2030". In: https://amazonia2030.org.br/o-projeto/ .
} 
que a palavra-chave neste contexto foi resiliência e que não somos uma comunidade à parte: a CRE está solidária a todas as dores do próximo e, também, esperançosa do futuro, apesar dos percalços. Três testemunhos apresentados foram impactantes: a do professor Celso Carias (que contou o que passou ao ser contaminado e vencer a COVID), a aluna Helena Bourgeois (que relatou como a pandemia a pegou de surpresa e o que fez para superá-la) e a aluna Neide dos Santos (que ressaltou o impacto da pandemia na sua vida econômica e de como foi importante toda a ajuda que recebeu e ainda recebe da Universidade). Em seguida, houve uma Missa pelas mais de 500 mil vítimas da pandemia e suas famílias. O aluno acima - F.P. - escreveu que achou muito interessante a Missa ser online, pois ele nunca havia assistido uma dessa modalidade.

\section{Conclusão}

Também aqui, peço a ajuda de duas alunas. A primeira, J.A.F.S., partilha que não é segredo para ninguém que estamos vivendo uma fase que não foi fácil: todos nós tivemos que nos reinventar e nos readequar! Neste contexto da pandemia da COVID-19, é importante ajudar ao máximo o próximo, estender a mão, ter empatia, repensar o mundo em que vivemos e quais são nossas prioridades. A pandemia nos fez refletir sobre a questão do cuidado com a sustentabilidade, o meio ambiente e a saúde - pontos essenciais para nossas vidas. No período anterior à pandemia, já era patente o descaso da sociedade para com o meio ambiente e a situação pandêmica mostrou que a sistematização predominante da sociedade atual possui falhas graves - houve uma desorganização global, para que criemos nova organização. É indiscutível que os principais temas do momento pandêmico são a recessão econômica e a busca por tratamentos eficazes e pela cura, mas é igualmente urgente proteger e regenerar o meio ambiente. Foram situações positivas: a redução da circulação de pessoas, uma melhora na qualidade do ar e o "retorno" de animais silvestres em diversos lugares do planeta; entretanto, é preocupante o aumento alarmante do desmatamento da Amazônia! A aluna G.G., por sua vez, partilhou em seu relatório que, ao participar da XXVII Semana, ela pôde perceber o quão rápido as mudanças em nosso planeta e em nossas sociedades estão acontecendo, e que as informações não possuem o mesmo peso de divulgação no meio social. Os webinares foram uma experiencia de visões que amplificam as questões mundiais do Planeta Terra - nossa Casa! Diante disto, ela sentiu uma forte necessidade de mudar hábitos, ficou mais motivada a se envolver com essas questões e a proliferar as informações que ela recebeu para que possamos, todos nós, cada um e sociedade, rever nossos conceitos e nossas atitudes por um futuro melhor!

\section{Webliografia:}

ÁGUA CAMELO. In: https://www.aguacamelo.com.br/ . AMAZONIA 2030. In: https://amazonia2030.org.br/o-projeto/ .

AUSJAL - Asociación de Universidades Confiadas a la a Compañía de Jesús en América Latina. In: http://www.puc-rio.br/ausjal/ .

CNN. "Painel da Vacina: Brasil segue como $68^{\circ}$ no ranking global e $4^{\circ} \mathrm{em}$ total de doses". 
In: https://www.cnnbrasil.com.br/saude/2021/06/23/painel-da-vacina-brasil-segue-como68-no-ranking-global-e-4-em-total-de-doses .

OLMA - Observatório Nacional de Justiça Socioambiental Luciano Mendes de Almeida. In: https://olma.org.br/ .

SACRU - Strategic Alliance of Catholic Research Universities. In: https://www.sacru-alliance.net/ 